\title{
Time History Analysis of Underground Water Tank for Different Seismic Intensity
}

\author{
Suraj Tripathi $^{3}$, Annu Dubey ${ }^{1}$, Madan Chand Maurya ${ }^{2}$ \\ ${ }^{1}$ Masters Student at Madan Mohan Malaviya University of Technology \\ ${ }^{2}$ Assistant Professor at Madan Mohan Malaviya University of Technology \\ ${ }^{3}$ Masters Student at Madan Mohan Malaviya University of Technology
}

\begin{abstract}
The Seismic analysis of an Underground water tank with reinforced concrete staging structure is analyzed in this paper, UG tank are used for storage of fluid for different use as per requirement. As we know that earth quake can occurring any time anywhere which may cause a saviour damage to our structure which may leads to loss of economy and life. To reduce Effect and minimize the consequence of seismic wave we may design our structure according to IS code provision.The time-history assessment study, carried out by a detailed finite element simulation of the UG water tank. For the study of nonlinear dynamic analysis we have used SAP 2000 software for different seismic intensity. The result of the study shows the deflected shape of tank at different condition considered as empty and full. Time history method becomes necessary to ensure safety against earthquake forces.
\end{abstract}

Keywords: Time History Analysis, Seismic responses, Underground water tank, SAP 2000

\section{Introduction}

In recent years the shortage of water occurs due to excessive use of water by human being. So due to that groundwater level decreasing drastically so for improving the groundwater level, we could use underground water and At the same time, the significant role they have played in the history of reinforced concrete design, and their elegant and imposing silhouette in urban and rural landscapes, prompted to include older overhead/UG water tank in the heritage listings of several countries, also situated in medium and high seismic prone areas worldwide. In view of this, a balanced preservation/seismic render strategy for these structures is currently required, based on the adoption of low impact rehabilitation methods respectful of their recognized architectural and engineering value. This tanks are widely being used For storage of large quantities of liquids like water, oil, petroleum, acid, and sometimes gases can also be stored like LPG/ Natural gas.

As we know there has been much importance on water supply projects all over the world, which are very essential for the social and industrial development of the country. Water tanks can be of different capacity depending upon the requirement of consumption. Based on the location the water tanks are classified into three ways:
a) Underground water tanks
b) Tank resting on grounds
c) Elevated or overhead water tanks.

\section{Classification}

\subsection{Underground water tank}

Underground water tank is used for storing fluids (oil, water, gas, etc.). These tanks are subjected to water pressure from inside and earth pressure from outside. The base of tanks is subjected to water pressure from inside and soil reaction from underneath. Always these are covered at the top. These tanks should be designed for loading which gives the worst effect. The design and principles of underground tanks are the same as for tanks resting on the ground. The walls of the underground tanks are subjected to the internal water pressure and outside earth pressure. Thesection of the wall is designed for water pressure and earth pressure acting separately as well as acting simultaneously.

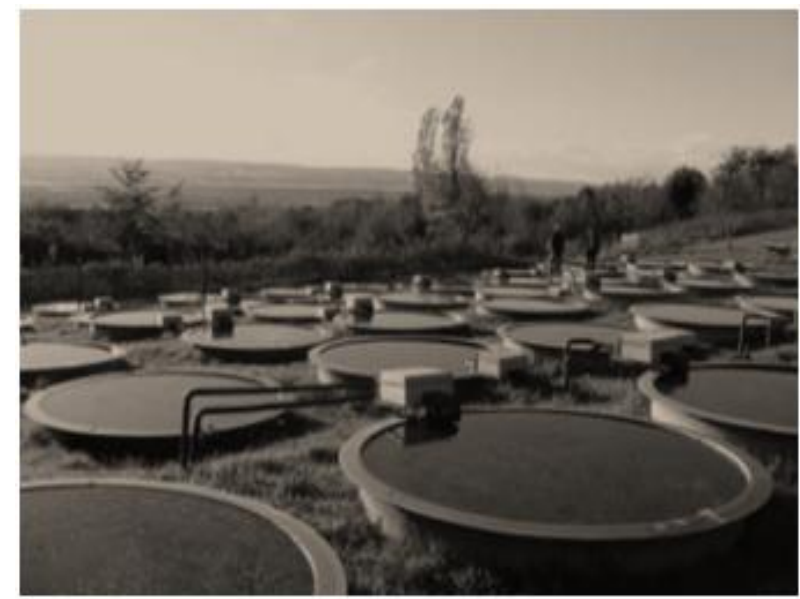

Figure 1: Photographic view of underground water tank

\subsection{Elevated or overhead water tanks}

Elevated or overhead water tank is supported on staging which may consist of masonry walls, R.C.C tower or R.C.C. column braced together. The walls are subjected to water pressure from inside. The base is subjected to the weight of water, the weight of walls and the weight of the roof. The staging has to carry a load of an entire tank with water and is also subjected to wind loads. Overhead water tanks of various shapes can be used as service reservoirs, as a balancing tank in water supply schemes and for replenishing the tanks for various purposes. Reinforced concrete water towers have distinct advantages as they are not affected by climatic changes, are leak-proof, provide greater rigidity and are adaptable for all shapes.

\section{Volume 9 Issue 6, June 2020}




\section{International Journal of Science and Research (IJSR) \\ ISSN: 2319-7064}

ResearchGate Impact Factor (2018): 0.28 | SJIF (2019): 7.583

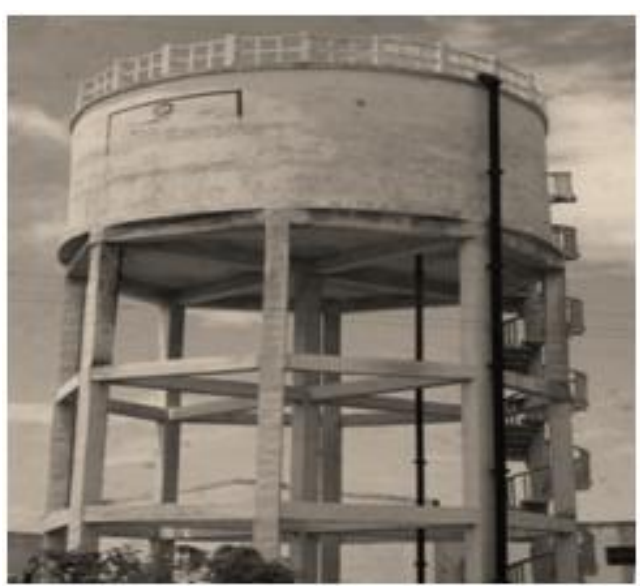

Figure 2: Shows Elevated water tank

\subsection{Tank resting on grounds}

This tank are resting on ground for the storage of potable water reservoirs, aeration tank etc. In this tank internal hydrostatics pressure is acting and outside pressure is not present except the base soil pressure the weight of water from inside and soil reaction form outside.

\subsection{Water tank is Also being classified based on shape:}

1) Circular tanks

2) Rectangular tanks

3) Circular tank with conical bottom

4) Spherical tanks

\section{Objectives}

1) Analysis UG water tank using Time History analysis method

2) Study the guidelines for the design of liquid retaining structure according to the IS Code.

3) To know about the design philosophy for the safe \& economical design of UG water tank.

4) The deflected shape of the tank is being analyzed

5) To reduce the tedious calculation

6) To compare the IS code design method with various software design results.

7) To understand governing loads and carry out a literature review related to the underground water tank.

8) To study the base deflection criteria, shell stresses and joint reaction of underground water tank structure by considering the dynamic type of loading when the tank is empty and full water level conditions.

\section{Structural Configuration Detail}

Table 1: Structure and site detail

\begin{tabular}{|c|c|c|}
\hline S no. & Location & Pune, India \\
\hline 1 & Length & $6 \mathrm{~m}$ \\
\hline 2 & Width & $4 \mathrm{~m}$ \\
\hline 3 & Thickness & $0.23 \mathrm{~m}$ \\
\hline 4 & Total Height & $3.5 \mathrm{~m}$ \\
\hline 5 & Seismic zone & III \\
\hline 6 & Capacity of UG Tank & 80000 litre \\
\hline 7 & Soil type & Medium \\
\hline 8 & Saturated Unit weight of soil & $18 \mathrm{Kn} / \mathrm{m} 2$ \\
\hline 9 & Unit weight of water & $10 \mathrm{Kn} / \mathrm{m} 2$ \\
\hline
\end{tabular}

Volume 9 Issue 6, June 2020 www.ijsr.net

Licensed Under Creative Commons Attribution CC BY

\begin{tabular}{|c|c|c|}
\hline 10 & Steel & Fe415 \\
\hline 11 & Concrete & M20 \\
\hline 12 & Angle of internal friction $(\varphi)$ & $30^{\circ}$ \\
\hline
\end{tabular}

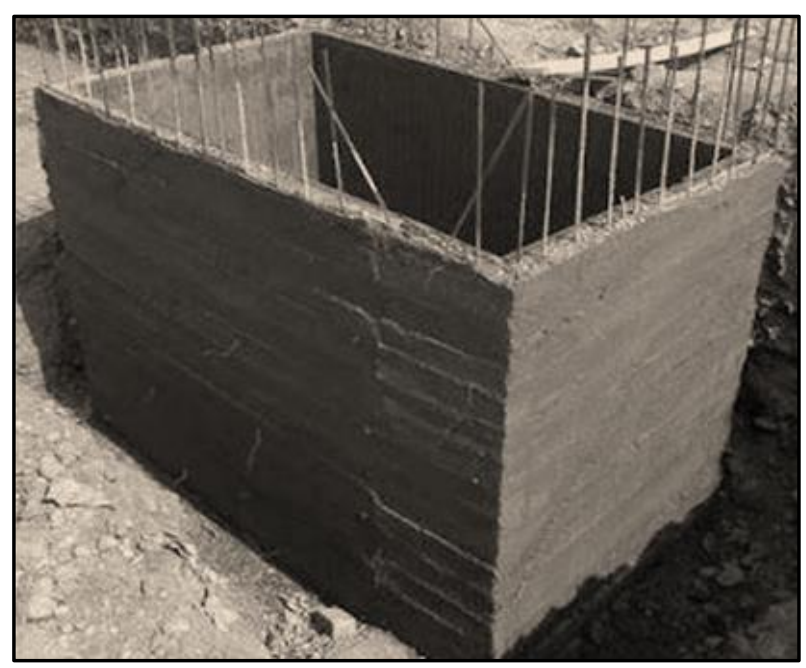

Figure 3: Photographic view of the UG tank at the time of construction

\section{Methodology}

At first analyze the rectangular shape UG water tank of capacity 80000 liter. The dimension of UG tank is $6 \mathrm{~m} * 4 \mathrm{~m} * 3.5 \mathrm{~m}$. IS:456 2000 is been used and for seismic analysis IS:1893 2002. Analysis is being done by the help of SAP 2000 software. After providing all required structural configuration we will assign time history data of Nepal earthquake which was happened in 2015/04/25 (LAMJUNG, NEPAL) magnitude of (7.8).

\subsection{Time-history performance assessment analysis}

Time history analysis (THA) is the use of an earthquake time history to evaluate the response of the system and the deformed shape by using SAP 2000 software. THA can be performed for both structures and soil. THA also provide REAL EQ time histories and also retains natural variation in the EQ time history. THA allows us to focus response on the period(S) of interest. This method is easy to perform with the help of proper tools.

Table 2: Different Time History Data Considered For Study

\begin{tabular}{|c|c|c|c|c|}
\hline S. No. & EQ & Date & $\begin{array}{c}\text { Magnitude } \\
\text { Richter Scale }\end{array}$ & P. G.A.g \\
\hline 1 & Bhuj, India & 26-Jan-01 & 6.9 & 0.11 \\
\hline 2 & Koyana, India & 11-Dec64 & 6.5 & 0.489 \\
\hline 3 & $\begin{array}{c}\text { Kanti Path, } \\
\text { Kathmandu, Nepal }\end{array}$ & 25-Apr-15 & 7.8 & 0.61 \\
\hline
\end{tabular}

Table 3: Different seismic Intensities considered for study

\begin{tabular}{|c|c|c|c|}
\hline S.No. & $\begin{array}{c}\text { Intensity } \\
\text { MMI }\end{array}$ & P.G.A.g & $\begin{array}{c}\text { Seismic Zones As } \\
\text { per IS: } 1893-2002\end{array}$ \\
\hline 1 & V & $0.03-0.04$ & - \\
\hline 2 & VI & $0.06-0.07$ & II (second) \\
\hline 3 & VII & $0.10-0.15$ & III (third) \\
\hline 4 & VIII & $0.25-0.30$ & IV (fourth) \\
\hline 5 & IX & $0.50-0.55$ & V (fifth) \\
\hline 6 & X & $>0.60$ & - \\
\hline
\end{tabular}




\section{International Journal of Science and Research (IJSR) \\ ISSN: 2319-7064}

ResearchGate Impact Factor (2018): 0.28 | SJIF (2019): 7.583

\subsection{Design steps for UG Rectangular Water Tank}

\subsubsection{Design steps are involving:}

1) Stability

a) Uplift Check b) Check of Stresses on Soil

\section{2) Strength}

a) Design of Critical Sections.
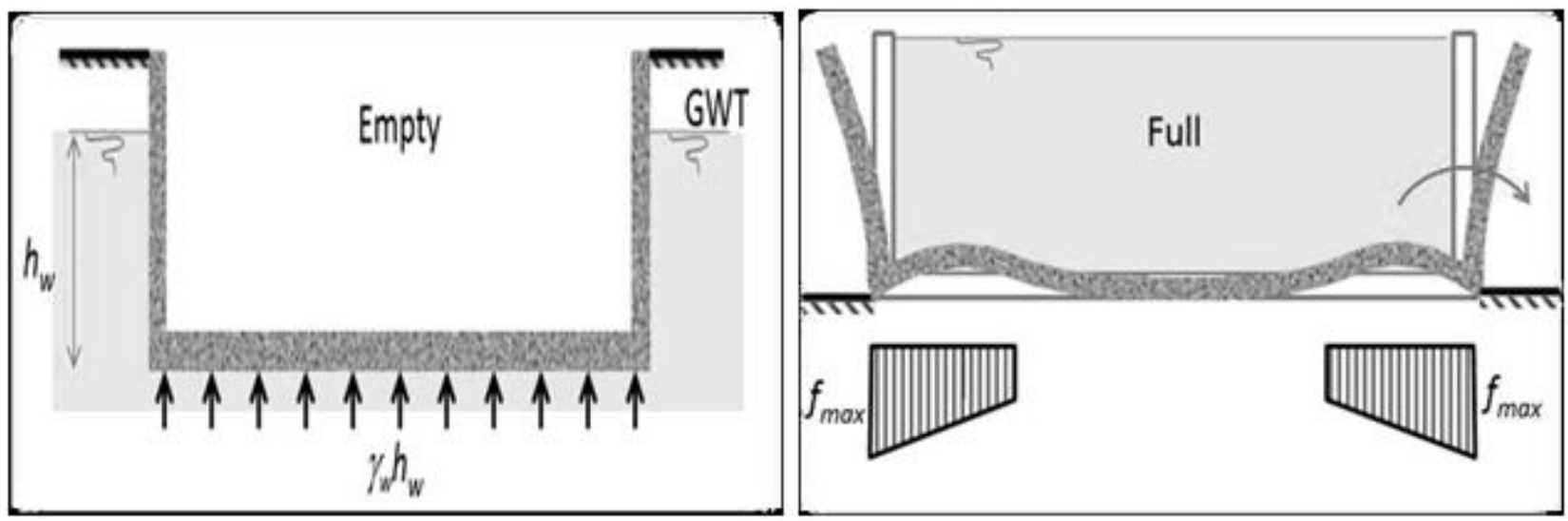

Figure 4: Sketches Show the results when tank is empty as well as full

\subsection{Structural Modeling and Analysis}

The finite element analysis software SAP 2000 nonlinear utilized to create 3D model and run all analysis. SAP 2000 software is able to anticipate the geometrical nonlinear behavior of space frames under static or dynamic loading, Both geometric non-linearity and material in-elasticity can be easily accounted by using this SAP 2000 .

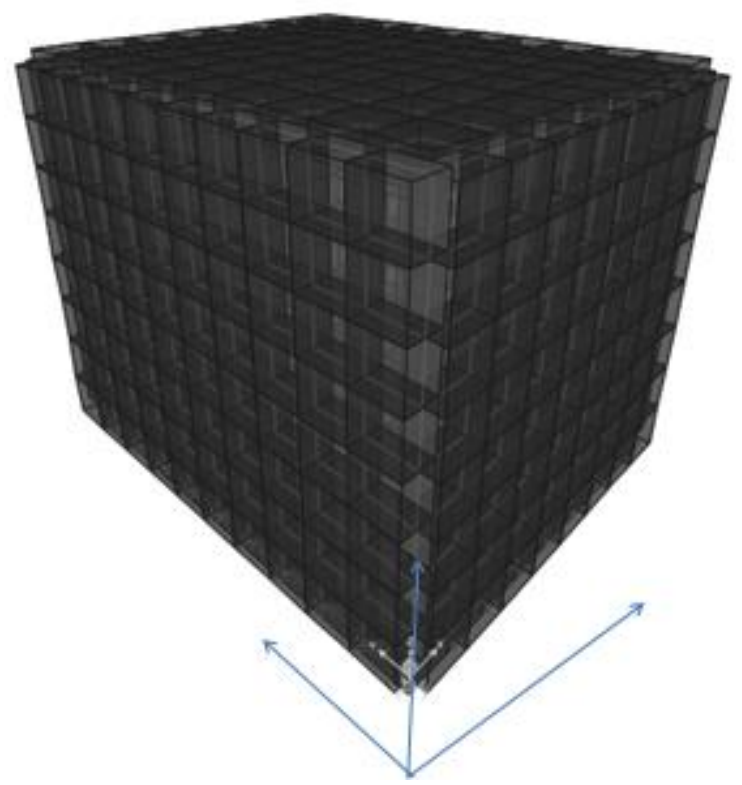

Figure 4: View of Finite model of UG water tank

\subsection{Load case detailing}

Figure 3 shows the load case detailing used in the design of UG water tank. For case 1 when tank is empty and only pressure acting is external soil pressure we will take load case as (DL+LL+soil pressure). For case 2 when tank is full then there will be load combination acting is (DL+LL+soil pressure+water pressure). All load combination will be having linear static type.

Volume 9 Issue 6, June 2020 www.ijsr.net 


\section{International Journal of Science and Research (IJSR) \\ ISSN: 2319-7064}

ResearchGate Impact Factor (2018): 0.28 | SJIF (2019): 7.583

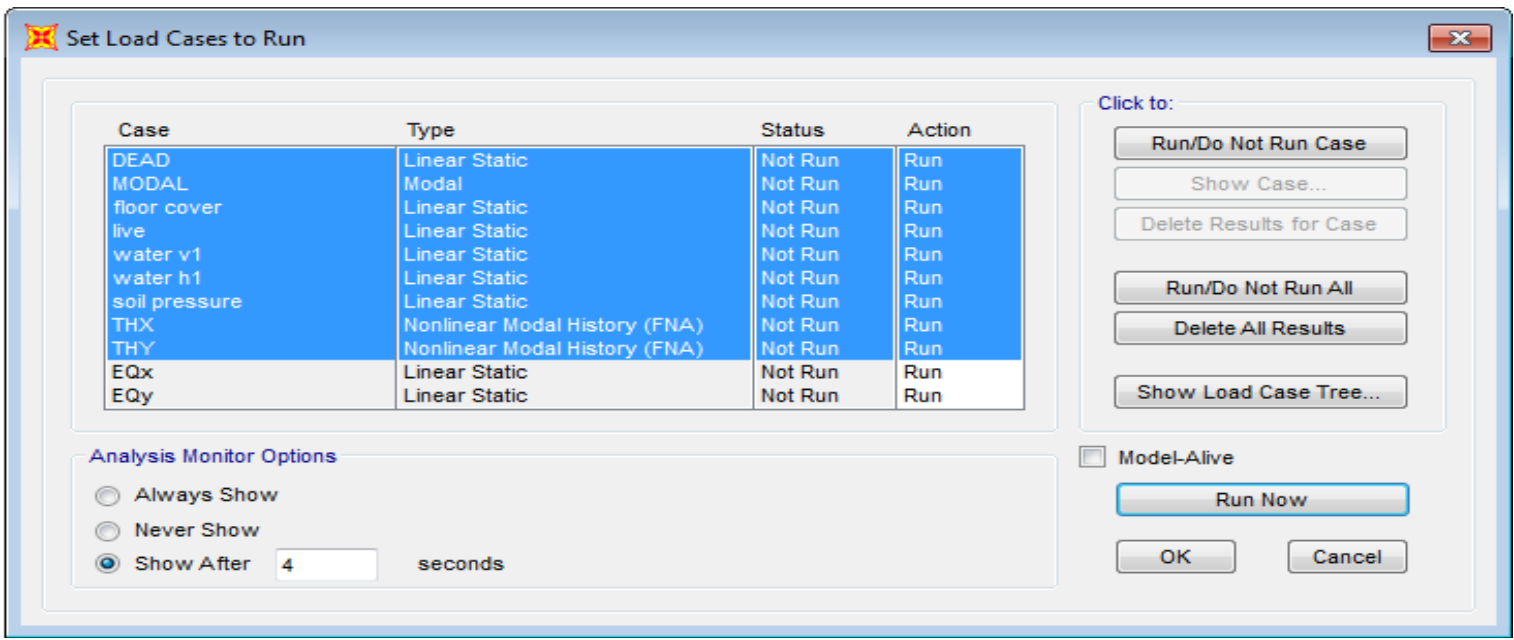

Figure 5: Shows the Load case detailing

\section{Result}

Case 1. When tank is full and hydrostatic and soil pressure are acting on it.

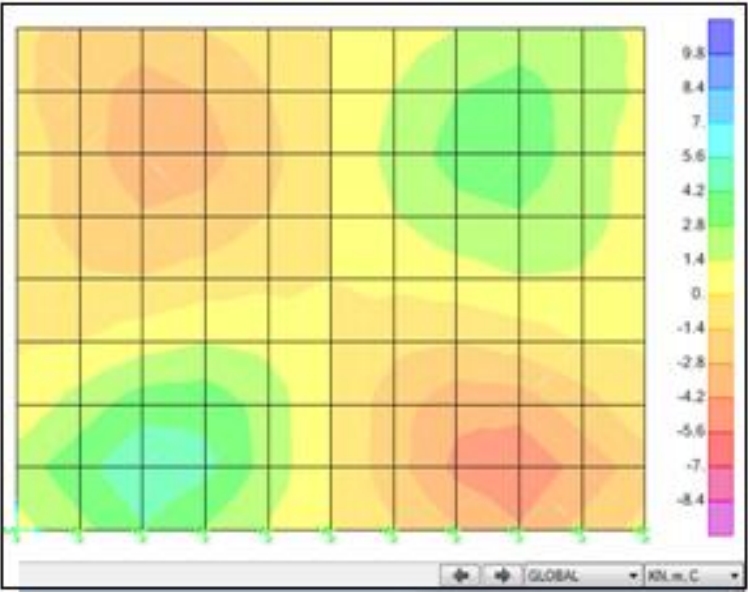

Figure 6: At the XY face of the UG tank we are getting Shell stress at component $\mathrm{f12}$ (xy) plane

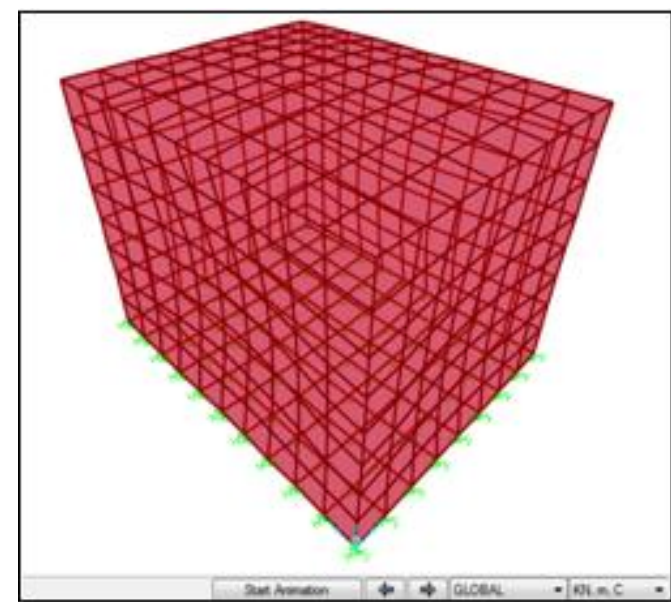

Figure 7: Deflected shape for case(1) of UG water tank due to THA when tank is empty and soil pressure is acting on it

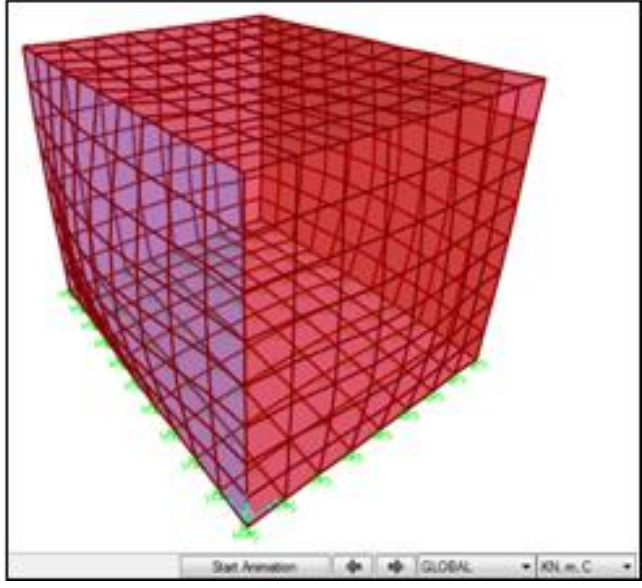

Figure 8: Deflected shape For case(2) when tank is empty and soil pressure is acting on it

\section{Conclusion}

The deflected shape of UG tank by the action of time history method for different case of storage is being determined Since time history analysis is a realistic and significantly used for the determination and design of better structure by considering factor of safety as per IS Code.On analyzing the structure with different time history data we get different mode of deflected shape for empty tank as well as for full tank for UG reservoir.

\section{References}

[1] Duggal S K (2010), "Earthquake Resistance Design of Structure", Fourth Edition, Oxford University Press, New Delhi.

[2] Haselton C B and Whittaker A S (2012), "Selecting and Scaling Earthquake Ground Motions for Performing Response-History Analyses", The 15th World Conference on Earthquake Engineering.

[3] Anvesh, N., Yajdani, S., \& Pawan, k. (2015). "Effect of mass irregularity on reinforced concrete Structure using ETABS". International Journal of Innovative Researchin Science, Engineering and Technology (IJIRSET),4(10).

[4] Suraj Tripathi and Annu Dubey (2020), "Detailed study of slope failure in rock" International Journal of

Volume 9 Issue 6, June 2020 www.ijsr.net 


\section{International Journal of Science and Research (IJSR) \\ ISSN: 2319-7064}

ResearchGate Impact Factor (2018): 0.28 | SJIF (2019): 7.583

Engineering Applied Sciences and Technology, 2020

Vol. 4, Issue 10, ISSN No. 2455-2143, Pages 213-215.

[5] IS: 3370 (Part 1st) - 1965, Code Of Practice For Concrete Structures For The Storage Of The Liquids.

[6] IS: 3370 (Part 2nd) - 1965, Code of Practice for Concrete Structures for the Storage Of the Liquids

[7] IS: 3370 (Part 4th) - 1965, Code of Practice for Concrete Structures for the Storage of the Liquids.

[8] IS: 3370 (Part 2) - 2009, Concrete Structures for the Storage of the Liquids - Code of Practice.

[9] Ramamrutan S, "Design of Reinforce Concrete Structures" (New Delhi : DhanpatRai Publishing Company Pvt .Ltd . 2006)

[10] Saroushnia S., Tafreshi S.T., F. Omidinasab, N. Behestian, "Seismic Performance of RC Elevated Water Tanks with FrameStagging\& Exhibition Damage Pattern", Science Direct, Procedia Engineering 14 (2011), Pp 3076 - 3087.

[11] Sudhir K. Jain and Medhekar M. S. October-1993, "Proposed provisions for a seismic design of liquid storage tanks" Journals of structural engineering Vol.20, No.-03.

[12] Ramamrutan S, "Design of Reinforce Concrete Structures" (New Delhi :DhanpatRai Publishing Company Pvt .Ltd . 2006).

[13]Dr.H.J. Shah "Reinforced Concrete Volume 2nd" (Gujarat, India: Charotar Publishing House Pvt Ltd 2012).

[14] NibeditaSahoo, "Design Of water Tank", Department Of Civil Engineering National Institute Of Technology Rourkela May 2008.. 